\title{
e-Learning and the aspect of students in forestry and environmental studies
}

Ioannis V. Kirkenidis ${ }^{1}$, Zacharoula S. Andreopoulou ${ }^{2}$

\section{N F O}

Received 1 Dec 2014

Accepted 1 Jan 2015

Available on-line 14 Jan 2015

Responsible Editor: M. Herdon

\section{Keywords:}

e-learning, agroforestry, ICT's,

European Union, higher education.

\begin{abstract}
$\underline{\text { A B S T R A C T }}$
The new information technologies (ICTs) and the services they provide, are tools that can transport data with high speed and allow the diffusing of vast amount of knowledge and information, in order to lay the groundwork to redefine a new improved relationship between person and environment with benefits that are important for both recipients. The need for a sustainable natural environment, based on sustainable facts, has led to the resurgence and support of systems such as agroforestry, whose services are vital to the life of modern man. This work will therefore focus on a presentation of modern technology and tools of e-learning, describes the current situation in the European Union and Greece, but also examine the need for the participation of these tools in agriculture and forestry courses, particularly those of agroforestry systems and the aspects of students in forestry and environmental studies. For that reason, finally presents results from a survey that took place amongst students of Faculty of Forestry and Natural Environment.
\end{abstract}

\section{Introduction}

New technologies have significantly entered our lives and online services offer the opportunity for sustainable regional development. Electronic services offered by the new Information and Communication Technologies (ICT's), have proved an important tool in efforts to disseminate e-learning in modern education. The technological background is excellent, while broadband networks provide quality communication and have ever increasing inflitration rates in our country. E-Learning is a very broad term covering anything relating to the use of modern technologies in education, whether implemented online, offline or a combination of both (Black, 2002; Koutroumanidis \& Andreopoulou, 2009) The concept of e-learning is quite general and includes any form of education using network resources or general capabilities of computers and education by distance. The e-learning courses can be categorized into synchronous and asynchronous depending on whether the students participate actively and in real-time or not. (Andreopoulou, Arabatzis, Koutroumanidis, \& Manos, 2006). E-learning may therefore be a tool for direct transmission of knowledge, without spatial limitations, knowledge that is needed to formulate the philosophy towards all crises which follow one another in the early 21 st century. No progress in the new Information and Communication Technologies (ICT's) would matter if there wasn't a specific application, with impact on society and on important aspects of human activities. Specifically, the comprehension and the total quality management of the environment is very important, with people learning about the natural environment and following practices which will lead to coexistence with it by pursuing sustainable development.

The agroforestry systems are a form of natural ecosystems multicultivation, which are fully exploiting the available natural resources, as of light, space, water and nutrients. The agroforestry, i.e. the intentional mixing of trees with crops and/or animal farming, is the key component of food and

\footnotetext{
${ }^{1}$ Ioannis V.Kirkenidis, phd candidate, Lab of Forest Informatics, Dept of Forestry and Natural Environment, School of Agriculture, Forestry and Natiral Environment Aristotle University of Thessaloniki, P.Box 247, GREECE

ibkirkenidis@for.auth.gr

2 Zacharoula S. Andreopoulou Assistant professor, Lab of Forest Informatics, Dept of Forestry and Natural Environment, School of Agriculture, Forestry and Natiral Environment Aristotle University of Thessaloniki, P.Box 247, GREECE randreop@for.auth.gr
} 
energy security in an unpredictable world affected by climate change and the shortage of fossil fuels (Schultz et al., 1987).

The agroforestry systems in our country consist of a large variety of trees and agricultural crops. The inventory of agroforestry systems at a national level is a high priority for their management and improvement. The importance of agroforestry ecosystems is reflected in the direction of the European Union, which in the recent EU Regulation 2013/1305, articles 21 and 23, defines that "agroforestry systems" are land use systems in which trees are grown in combination with agriculture on the same area (Papanastasis, 2014).

The first European Conference on agroforestry in Brussels, with participants from 17 European countries as well as representatives from America and Africa, organized by the European Federation of Agroforestry (EURAF), discussed the obvious and remarkable productivity and the efficient supply of ecosystem services of agroforestry systems. The agroforestry systems include all the spatial arrangement of trees at the boundary or within cultivated or grazed fields. The high productivity of agroforestry systems, namely an increase in land productivity up to $40 \%$ without additional inputs, is demonstrated in controlled experiments and testimonies from farmers. The agroforestry is also part of the solution to the challenge of bio-energy, which Europe is facing in the current period and can provide opportunities for employment, which cannot be ignored. The range of agroforestry ecosystems include mitigation and adaptation of climate change, control of soil erosion, protection of water, conservation of biodiversity and protection from fires in dry areas and generally all the benefits of agroforestry systems for mitigation and adaptation to climate changing (EURAF, 2012). It is obvious how important these systems are in Europe and in Greece, so we have to deal with them more and, while taking advantage of the use of new technologies in learning and in media, achieve the best but also the most massive diffusion of knowledge and information.

This paper is an attempt to capture the perspectives on e-learning for environmental issues in European Union, while in more details it is attempted to describe modern technology on the e-learning, with simultaneous presentation of modern tools, and description of the current situation about e-learning and especially in the EU and Greece. Furthermore, presents results from a survey that took place amongst students of Faculty of Forestry and Natural Environment, about their views on e-learning issues in relation to their integration into the curriculum.

\section{Methodology}

In order to achieve the objective of this paper, a research was carried out and depicted the kinds of elearning and also presented the modern tools used to create e-learning courses. Research was expanded to include the recording and the description of the current situation, the relevant developments and the guidelines within the EU and Greece. Moreover a survey took place among students of forestry, to determine the dissemination of new technologies in their social and academic lives and to explore their views on the design and implementation of an e-learning program that will cover their curriculum as well as agroforestry issues.

The survey that took place for this paper was performed with the method of questionnaires. It took place in the period from May to September 2014. The sample size was calculated with the simplified formula of Yamane (Yamane, 1967),

$$
n=\frac{N}{1+N * e^{2}}
$$

where $\mathrm{n}$ is the sample size, $\mathrm{N}$ is the number of the population of interest, and e the precision level (level of precision $=0.05$ ) with $95 \%$ confidence level and volatility $\mathrm{P}=0.5$.

While applying the formula (1) and taking into account that the number of students in Forestry is 732 , we find the sample size, which is 259 . 


\section{Results}

The concept of e-learning is quite general and includes any form of education that uses network resources or capabilities of computers in general and distance education (e-learning). The variations in the configuration of the offered e-learning platforms can be described by a number of characteristics. These features can be classified into synchronism, location, independence, and learning styles. (Wagner, Hassanein, \& Head, 2008)

\section{1 e-learning perspectives}

In order to define the concept of e-learning better we distinguish four different types of e-learning: Self-paced training or independent e-learning, Asynchronous e-learning, Synchronous e-learning, (Ruttenbur, Spickler, \& Lurie, 2000) and the Blended e-learning which is the most common today. The context of e-learning has the potential to provide guidance to : 1. planning and designing e-learning materials, 2. the organization of resources for e-learning environment, 3. the design of distributed learning systems, corporate universities, virtual universities and cyberschools, 4. the design of LMS, LCMS and integrated authoring systems (e.g., Omni), 5. the evaluation of courses and e-learning, 6. the assessing of authoring tools / e-learning systems, LMS and LCMS. 7. the design and evaluation of blended learning environments. Khan identifies e-learning as a multidimensional system in a framework, in order to capture the structure and requirements of e-learning to address issues comprising eight dimensions, (Khan, 2001).

The modern e-learning applications are a very important innovation for distance education, since they combine new ways of presenting information and offer opportunities for direct communication and interaction (Belanger \& Jordan, 2000; Latchem, 2002). The effective use of modern e-learning systems and the formulation of reliable criteria for effectiveness of teaching / learning process is a matter of negotiation for the scientific community. According to many researchers videoconferencing systems are not just a technological tool in the field of distance education, but have profound educational and pedagogical implications (Harasim, 2000; Kerrey \& Isakson, 2001).

As Baker says there are three major reasons why the Open Universities promote electronic sessions (Baker et al., 1996): overcomes the isolation of remote students, encourages the exchange of ideas and learning experiences, improves the distant delivery and presentation of learning materials through a structured and supportive environment. Certain software which can incorporate e-learning is required for the realization of e-learning, but one system cannot replace the other because they support dissimilar learning activities. This can be a LMS (Learning Management System) which is a course management system, supporting a number of short training events or a CMS (Content Management System) which supports long sessions of courses.

An LMS (Learning Management System) is a course management system covering the learning needs of registered members. It focuses more on learning information and less on learning itself. It is software for the management, documentation, monitoring and reporting of training programs, online events, e-learning and educational content (Ellis, 2009). Changes susceptible to the system are limited, likely to create problems regarding the adjustment needed to meet the various needs of individual institutions that use it. One of the most famous used in Greek higher education are the Open eClass, Moodle, BlackBoard, Sakai, Scientix etc.

The Content Management System (CMS) is a form of computer software that automates the creation, organization, control and publication of content in a variety of forms. Most CMS have the ability to manage content in the following formats: text, images, video, java animation, design patterns, databases etc. Many times a CMS allows the creation of a group of texts and other material and that is why it is so often used, for example, in the educational programs of many companies. A Web Content Management System and Web Publishing System is a form of computer software that provides additional features to facilitate the necessary work in publishing content online through a website. Some of the most popular content management systems are WordPress, Joomla, Drupal, etc.

Virtual Classroom. The possibility of video conferencing has created intense interest in the possibility of 'simulation' of the functions of the educational process, as it is carried out in normal rooms, 
in virtual classroom environment (virtual classrooms). Just as the term virtual implies a reality simulation, the virtual classroom is a simulated classroom via Internet, which provides a comfortable communication environment just like in a traditional classroom. A virtual classroom allows students to attend a course from anywhere in the world, and aims to provide a learning experience that is similar to a real class (Jadhav, 2006).

Past experience of utilizing the applications of new information and communication technologies has shown that the mere transmission of audiovisual information and face to face communication, do not necessarily contribute to the effective achievement of the cognitive objectives if not accompanied by appropriate teaching and learning activities, inviting the student to participate actively in all phases of the learning process. The effective use of applications of new information and communication technologies must follow the principles of modern constructive approaches to learning, which focus on proper coordination of learning activities, communication, ensuring greater opportunities for two-way interaction (two-way interactive communication) of the participants with each other and with conciliator tools, in the constructive nature of knowledge and creative engagement of students in the educational process (Willis, 1994). The best known and most widely distributed virtual classrooms are Blackboard, WizIQ, moodle Udemy, Peer 2 Peer University (P2PU) Learnopia etc. The main features of the virtual classroom are the ability to engage multimedia experience, the removal of geographical constraints, the ability of recording sessions, the faster organising of courses, the one-to-one communication, the fact that is easy-to-use and, finally, the support that it offers to what happens before and after a live session. The emerging virtual environment and the virtual classrooms come to meet the communication gap caused by distance learning (Arbaugh, 2000). Utilizing greatly the possibilities presented by the new technologies, virtual classrooms offer high-level interactions and opportunities for collaboration, crucial elements for the acquisition of knowledge.

The model "anyone - anywhere - anytime" is not the future of e-learning (Ruttenbur et al., 2000). Its true potential is the ability to offer the right information to the right people at the right time and place. Learning systems based on web services (Web Based Learning Systems) will revolutionize e-learning because they will provide personalized, interactive, relevant and user-centred learning tools.

\section{Current situation in Greece, European Union and U.S.A.}

Web 2.0 technology, led e-learning systems forward. Theorists and researchers continue to develop new tools and systems along with emerging web technologies.

United States of America: 65\% of university colleges in the USA in 2004 offered online undergraduate and postgraduate courses at a rate of 44\%.(E.I. Allen \& Seaman, 2005). Over 5.6 million students (nearly $30 \%$ of the total) attended at least one online course in the fall semester of 2009 , with annual growth rate of $21 \%$, while the increase of students was only $2 \%$. The $66 \%$ of rectors believe that the learning outcomes of online education are equal or superior to those of classroom teaching (E. Allen \& Seaman, 2010).

European Union: The use of e-learning in Europe is generally very limited compared to the USA. In 2000 started an effort to incorporate technologies of informatics and communications (ICT) in education and training. The first attempt of teaching courses using synchronous e-learning was conducted by the Department of Information Systems University of Budapest (CUB) in students of Selye University, Komarno in Slovakia in 2000.

In May 2000, the European Committee proposed the e-learning initiative for achieving the objectives set by the Lisbon European Council, namely to make the European Union the most competitive economy in the world based on knowledge. (Council Resolution on eLearning EU, 2010) Similarly, in the field of vocational training, appears Ericsson Education, which created an integrated program of blended elearning. In the European project INFO-2000 joined acts such as «Socrates», «Leonardo da Vinci» and «e-Learning», with most important goals for the last one being the familiarization with digital media (digital literacy), the virtual campuses and the twinning of schools (e-Twinning) (decision 2003/2318 / EC). Thus began to form a culture of e-learning since 65\% of European universities in a survey in 2003 indicated that such services are an important priority for the future. 
Significant differences between European countries (culture, language, technology, economic status, etc.) are reflected in the different penetration of e-learning in each of them. Increasing use of the Internet for education in Greece and other Mediterranean countries (Figure 1) may be due to the economic situation of the population in these countries, which now considers the transition to other Member States and / or other cities of the same Member State prohibitive. At the same time, while in France is documented a stagnancy with a slight decline in 2011 and a slight increase in the United Kingdom, there is a great increase in the southern Member States, such as Greece, Cyprus, Spain, Bulgaria, Romania, Spain and Portugal. In particular we observe that Greece, after staying stable in the years 2007-2010, report a surge in 2011 , from $12 \%$ to $20 \%$.

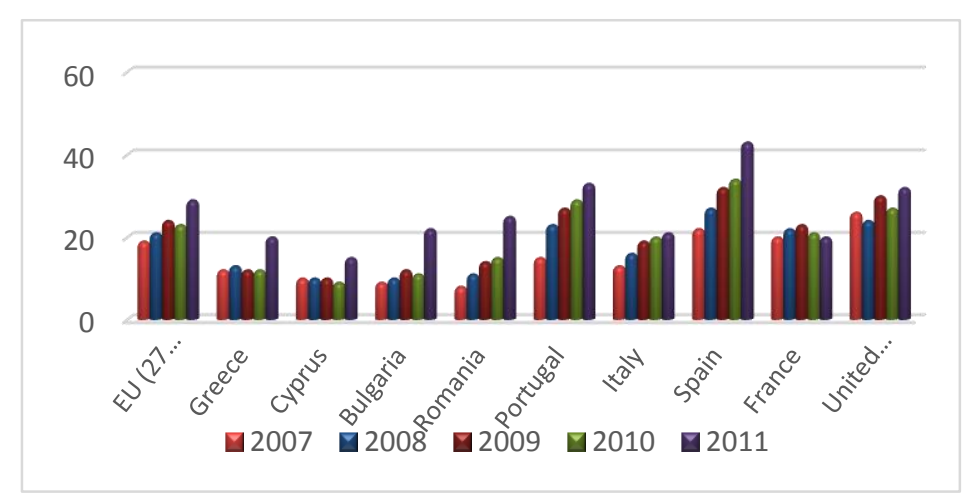

Figure 1. People using the Internet to search information on education (2007-2011) \% of people aged 16-74 years, in South Europe, the Balkans and the East Mediterranean. Source: (Eurostat, 2013)

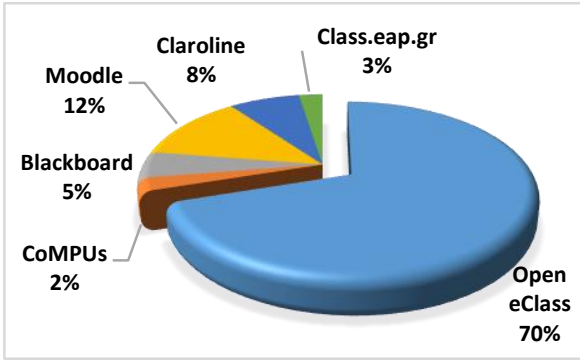

Figure 2. E-learning platforms in Greek higher education

Greece: The European policies are followed at a satisfactory pace. The Greek School Network, the Greek Open University, but also vocational training programs of tertiary institutions and programs of public bodies are some of the steps that Greek organizations are making on the path of e-learning. Advanced modern e-learning infrastructure created in specially designed rooms at the National Technical University of Athens (NTUA), National University of Athens (UOA) and the Athens University of Economics and Business (AUEB).

The Highest Educational Institutes, have already incorporated e-learning modules with over 1000 online courses. More specifically, for the modules of the online courses in Universities, $42.4 \%$ were presentations of lectures, with only textual notes was $36.69 \%$. The use of multimedia in the form of audio-visual material (video and audio files) found in a very small percentage of $5.42 \%$. An interesting feature was that while the presentations were split into smaller sections, the texts, with few exceptions, were a single entity covering the whole curriculum.

It was striking, however, that only $12.1 \%$ of the programs provided the opportunity of group discussions, but again the participation of students was negligible, while the provision of activities to enable students included exercises (20.6\%) which involved solutions and / or examples in an even smaller percentage (17.5\%).

Regarding used e-learning platforms, from a total of 38 higher education institutions, $70 \%$ use the Open eClass, while the second is Moodle with 12\%, the third Claroline 8\%, the Blackboard 5\%, followed by other platforms with smaller rates (Figure 2).

\subsection{Results of the survey}

In schools and departments with fields related to Agriculture, Forestry and Environment, there are educational e-learning programs, but most of them only contain course notes and lecture presentations. But the addition of the lectures in the form of video is in progress in the Aristotle University of Thessaloniki in several of these modules. The research that took place amongst students of the Faculty of Forestry and Natural Environment, aimed to investigate the penetration of new technologies in everyday life and the structure of e-learning that they would prefer. 
For this reason a pilot research conducted to 272 students of Forestry and Natural Environment according to methodology, in which it was found that $100 \%$ of the students questioned use the Internet, $85 \%$ use the internet from tablet or mobile phone, and $74 \%$ would like the potential usage of e-learning platform through mobile application and only 5\% have attended a course through an e-learning platform, although none of them related to environmental, forestry or agricultural topic.

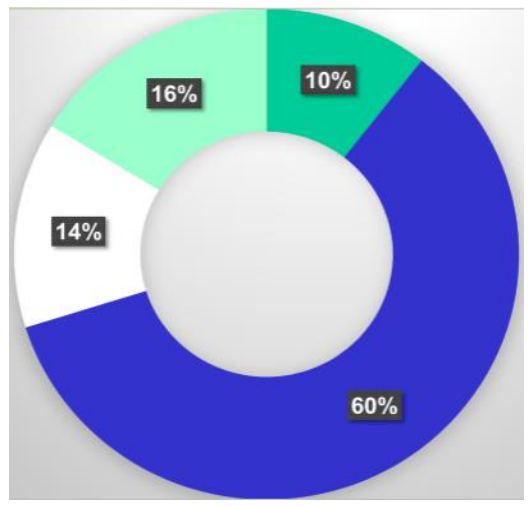

Figure 3. Attending e-learning classes

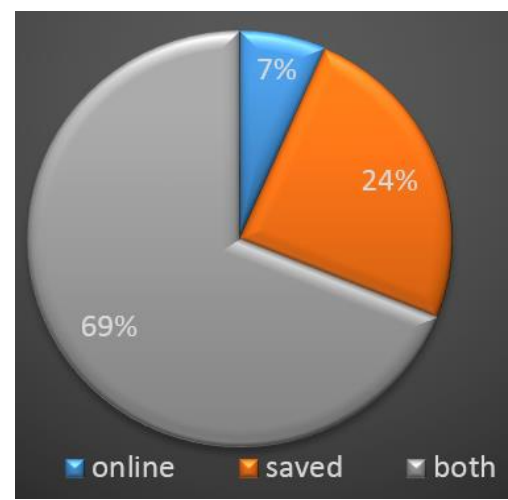

Figure 4. How do you like to have the courses

A minimum of $10 \%$ think that lessons of geotechnical content can be taught with e-learning (Figure 3 ), as opposed to $74 \%$ who believe that there are factors that affect this possibility (teacher, students and platform).

About the online or not carrying on of the e-learning course, (Figure 4) $7 \%$ prefer the online presentations with a specific timetable, $24 \%$ prefer stored video files while $69 \%$ prefer the online presentations and then stored in the form of video available to them.

Table 1. Most significant rated characteristics in an e-learning session

\begin{tabular}{|c|c|c|c|c|c|}
\hline Characteristic & $\%$ & Characteristic & $\%$ & Characteristic & $\%$ \\
\hline Notes & 86.4 & Suggestions & 53.1 & Bibliography & 42.5 \\
\hline Papers & 75.1 & Multimedia & 52.2 & Examinations & 41.7 \\
\hline Contact by email & 72.8 & on-line papers & 49.1 & Tests & 34.2 \\
\hline FAQs & 63.6 & Class discussions using chat room & 48.6 & Feedback & 22.8 \\
\hline on-line help & 60.5 & Communication via on line bulletin board & 45.6 & Contact by SMS & 19.3 \\
\hline
\end{tabular}

Regarding the most significant information, between 15 options, that should be included in an elearning platform, $86 \%$ chose course notes, papers $(75 \%)$, followed by e-mail contact $(72.8 \%)$, frequently asked questions $(63.6 \%)$ and online help $(60.5 \%)$. All options with their percentages are presented in Table 1.

For examinations - evaluations of e-learning courses (Figure 5), 50\% prefer a physical presence in the room (traditional method) with 29\% preferring on-line tests (both limited and unlimited duration, with or without automatic feedback), and forwarded via internet papers (21\%).

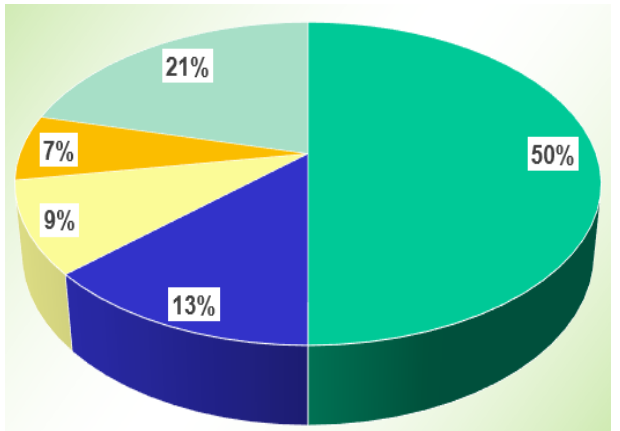

Figure 5. Preferable evaluation pattern

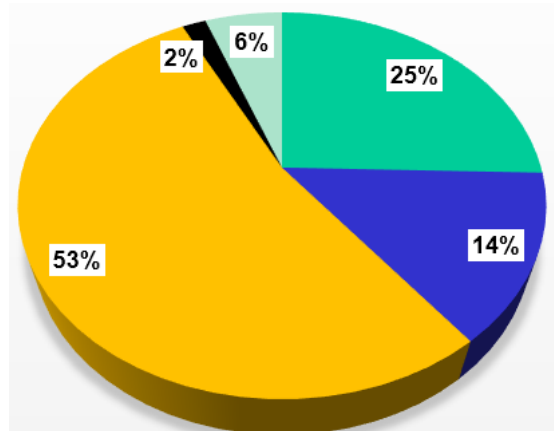

Figure 6. Need of instructor's physical presence 
In the matter of the physical presence of the instructor (Figure 6), 53\% believe that it is essential, $14 \%$ that it is necessary only for the learning of skills while $25 \%$ claim that there is no need for physical presence but it is necessary for answering questions, of which $49 \%$ felt the need for the physical presence of the instructor more than twice per semester, $29 \%$ for twice per semester and $18 \%$ for once per semester. As for the preferable amount of live audiovisual communication with the instructor, $69 \%$ responded once a week, $23 \%$ once a month, while $8 \%$ think it is not needed, as long as they have answers to their questions via Forum, chat room or email (Figure 6).

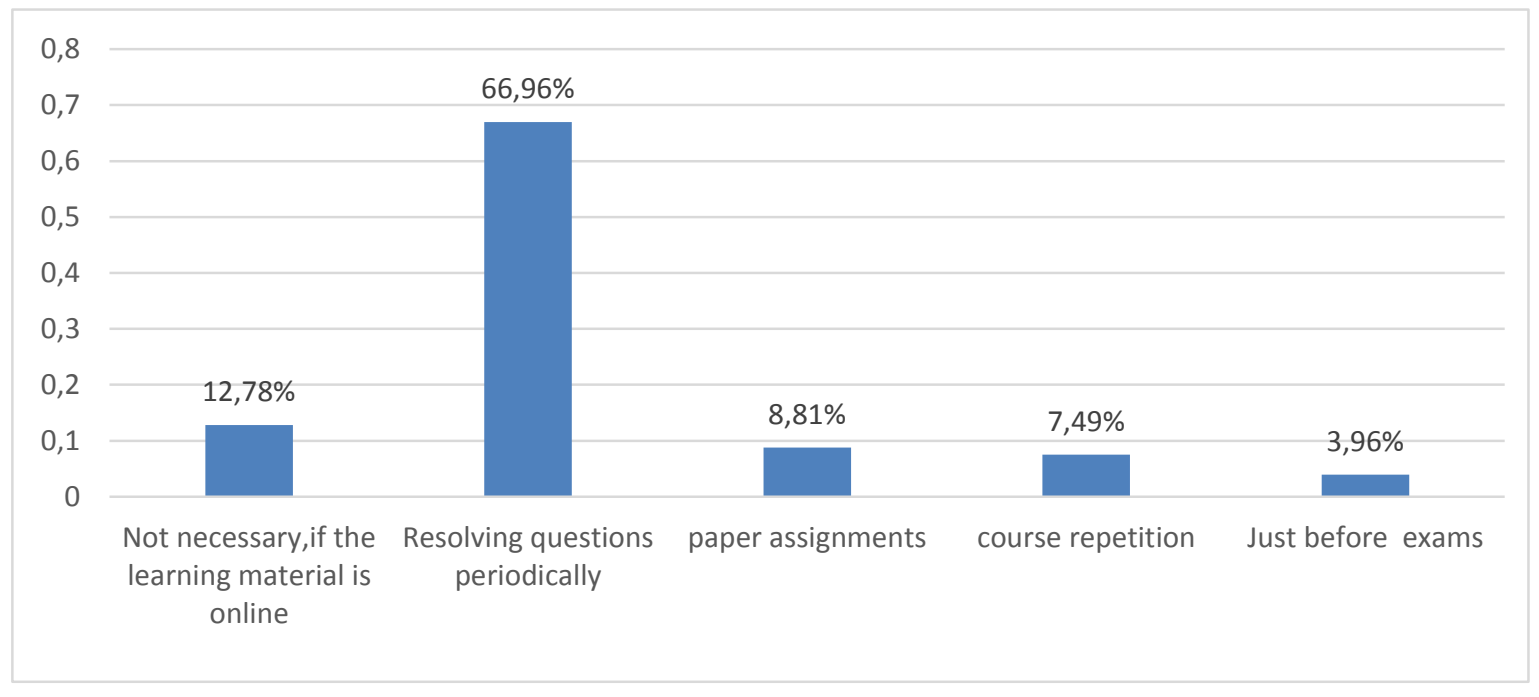

Figure 7. When virtual class is considered the most useful

For the running of virtual classroom $66.7 \%$ believe that it is useful for resolving queries at regular intervals and there is a $12,8 \%$ who believe it is not necessary as long as they can find the proper study material online (Figure 7).

Finally, in a question about the agroforestry systems that they would be interested to be informed further, 57\% chose the silvoarable systems and followed by the agrosilvopastoral (33\%) and the silvopastoral (10\%).

\section{Discussion - future challenges}

The use of e-learning in Europe is generally very limited compared to the USA, but there is a lot of effort in that direction, in EU Council, so that such services are an important priority for the future. There is a great increase in use of the Internet for education in Greece. The results of the research show us that the responding students of Forestry, are users of the Internet, but also of programs and applications of new information and communication technologies. On the issue of e-leaning though, they have no experience and this urges them into conservative responses particularly in relation to the presence of the teacher, the pace of meetings with physical presence or via teleconference and the examination pattern. The rest of the answers, however, can be considered a first step, a basis for how a module of an e-learning course should be structured and what it should contain.

Based on the above and on the basis that agroforestry and its reintegration in common daily practice is an important development that should have the similar communication dissemination. That is the reason, it is necessary to extend the research, under the correct and thorough creation and operation of an e-learning platform for teaching and diffusion of knowledge about agroforestry issues and their positive effects (environmental, economic, social, psychological). Firstly, the research should include the views and opinions of students in agricultural schools who will attend the online courses. On the other hand, research will be conducted about the opinions of experts on the structure of the e-learning course, with the simultaneous provision for its needs in the near future. From the results of these researches and thorough international practice, should be possible to structure and draft a comprehensive e-learning module covering comprehensively the subject of agroforestry topics, in order to teach students in agricultural, forestry and environmental faculties, but also to enable ordinary people to be informed about developments in this matter. 


\section{References}

Allen, E. I., \& Seaman, J. (2005). Growing by Degrees (p. 30). USA: The Sloan Consortium.

Allen, E., \& Seaman, J. (2010). Class Differences: Online Education in the US, 2010, marks the end of an era. (p. 30). USA: Babson Survey Research Group.

Andreopoulou, Z. S., Arabatzis, G., Koutroumanidis, T., \& Manos, B. (2006). E-learning Model for the Afforestation of Agricultural Land. In 18th Conference of the Hellenic Society for Operational Research HELORS 06, with title "Planning, Information Retrieval and Knowledge Management" (pp. 661-670.).

Arbaugh, J. B. (2000). Virtual classroom characteristics and student satisfaction with internet based MBA courses. Journal of Management Education, 24(1), 32-54. doi:10.1177/105256290002400104

Baker, C., Tomlinson, N., Cole, S., Stevens, V., George, J., Howwells, A., \& Thorpe, M. (1996). Support for Open Learners: Reader. The Open University, SUP 34725 .

Belanger, F., \& Jordan, H. D. (2000). Evaluation and implementation of distance learning - Technologies, tools and techniques. USA: Idea Group Publishing. doi:10.4018/978-1-878289-63-6

Black, G. (2002). A Comparison of Traditional, Online and Hybrid Methods Of Course Delivery. Journal of Business Administration Online, Spring, 1 (1). Retrieved from http://jbao.atu.edu/old/Journals/black.htm

Council Resolution on eLearning E.U., . (2010). European Union legilation. Retrieved March 17, 2013, from http://europa.eu/legislation summaries/education training youth/lifelong learning /c11052 en.htm

Ellis, B. R. K. (2009). Field Guide to Learning Management Systems. Learning Circuits, 8.

EURAF. (2012). EUROPEAN AGROFORESTRY FEDERATION. Retrieved March 08, 2013, from http://www.agroforestry.eu/

Eurostat. (2013). Individuals using the Internet for looking for information about education, training or course offers. Retrieved from http://epp.eurostat.ec.europa.eu/tgm/table.do? tab=table\&init $=1 \&$ plugin $=0 \&$ language $=$ en $\&$ pcode $=\operatorname{tin} 00034$

Harasim, M. (2000). Shift happens: online education as a new paradigm in learning. The Nternet and Higher Education, 3, 41-61. doi:10.1016/s1096-7516(00)00032-4

Jadhav, S. K. (2006). The Virtual Classroom. (v, Ed.) (p. 72). Navi Mumbai. doi:10.1037/e589222007-001

Kerrey, B., \& Isakson, J. (2001). The Power of the Internet for Learning: Moving from Promise to Practice. Report of the Web-based Training Educational Commision (p. 55). Washington DC.

Khan, B. H. (Ed.). (2001). Web-Based Training. Educational Technology Publications.

Koutroumanidis, T., \& Andreopoulou, Z. S. (2009). E-lEarning in thE intErnEt supporting quality oF liFE and EnvironmEnt within sustainability in thE Eu. Journal of Environmental Protection and Ecology, 10 (4), $1227-1242$.

Latchem, C. (2002). ICT-based Learning Networks and Communities of Practice. Media and Education, National Institute of Multimedia Education (NIME), 8, 1-13.

Papanastasis, V. (2014). Agroforestry systems in the new CAP (2014-2020). Agriculture and Livestock, 3 ( Agrotypos), 36-42.

Ruttenbur, B., Spickler, G. C., \& Lurie, S. A. (2000). E-learning The engine of the knowledge economy. (New York: Morgan Keegan \& Co. Inc. Members New York Stock Exchange).

Schultz, M. A., Papanastasis, V., Katelman, T., Tsiouvaras, C., Kandrelis, S., \& Nastis, A. (1987). Agroforestry in Greece.

Wagner, N., Hassanein, K., \& Head, M. (2008). Who is responsible for E-Learning Success in Higher Education? A Stakeholders' Analysis. Educational Technology \& Society, 11 (3), 26-36.

Willis, B. (1994). Distance Education Strategies and Tools. In Research in distance education (p. 61). doi: $10.5860 /$ choice. $32-1655$

Yamane, T. (1967). Statistics, An Introductory Analysis (2nd Edition). New York: Harper and Row. 